\title{
A Comparative Study of Effect of Intravenous Lidocaine Infusion, Gabapentin and Their Combination on Postoperative Analgesia after Thyroid Surgery
}

\author{
Sahar El Shal \\ Faculty of Medicine, Cairo University, Cairo, Egypt \\ Email: sasmed_2006@yahoo.com
}

How to cite this paper: El Shal, S. (2017) A Comparative Study of Effect of Intravenous Lidocaine Infusion, Gabapentin and Their Combination on Postoperative Analgesia after Thyroid Surgery. Open Journal of Anesthesiology, 7, 296-314.

https://doi.org/10.4236/ojanes.2017.79030

Received: August 3, 2017

Accepted: September 25, 2017

Published: September 28, 2017

Copyright $\odot 2017$ by author and Scientific Research Publishing Inc. This work is licensed under the Creative Commons Attribution International License (CC BY 4.0).

http://creativecommons.org/licenses/by/4.0/ cc) (7) Open Access

\begin{abstract}
Objective: This prospective randomized study aimed to evaluate the effect of IV lidocaine infusion or gabapentin and their combination in providing efficient analgesia after thyroid surgery. Methods: Eighty-eight patients scheduled for thyroidectomy were randomized into four equal groups $(\mathrm{n}=22)$. Group P (placebo) patients received placebo capsules $1 \mathrm{~h}$ preoperatively and intravenous (IV) saline infusion. Group L (Lidocaine): patients received placebo capsules $1 \mathrm{~h}$ preoperatively and IV bolus lidocaine $1.0 \mathrm{mg} / \mathrm{kg}$ followed by infusion $2 \mathrm{mg} / \mathrm{kg} / \mathrm{h}$. Group G (Gabapentin) patients received $600 \mathrm{mg}$ gabapentin capsules $1 \mathrm{~h}$ preoperatively and IV saline infusion. Group LG (Lidocaine-Gabapentin) patients received $600 \mathrm{mg}$ gabapentin capsules $1 \mathrm{~h}$ preoperatively and IV bolus of $1.0 \mathrm{mg} / \mathrm{kg}$ lidocaine followed by infusion $2 \mathrm{mg} / \mathrm{kg} / \mathrm{h}$. (lidocaine or saline infusion started before induction of anesthesia and continued until the end of surgery). Intraoperative fentanyl consumption and hemodynamic changes were recorded. Postoperative total tramadol consumption, time to first analgesic request, visual analog scale (VAS) of pain, sedation level, and side effects were assessed for 24 hours. Results: (LG) group had significant lower intraoperative fentanyl and lower postoperative tramadol consumption $(\mathrm{p}<0.001)$ compared to $(\mathrm{P}),(\mathrm{L})$ and $(\mathrm{G})$ groups, with prolonged time of first analgesic request $(\mathrm{p}<0.001)$ compared to $(\mathrm{P})$ and $(\mathrm{L})$ groups, and lower VAS compared to other groups ( $\mathrm{p}<0.001$ or $\mathrm{p}<0.01$ ). There was significantly lower postoperative nausea and vomiting (PONV) in G \& LG groups compared to $(\mathrm{P})$ group $(\mathrm{p}<0.01)$. Conclusion: The combination of preoperative gabapentin and intraoperative lidocaine infusion provided more analgesic effect than either drug alone with lower and more delayed postoperative analgesic requirements and lower VAS. (PONV) was lower in groups
\end{abstract}


received gabapentin.

\section{Keywords}

Lidocaine, Gabapentin, Thyroidectomy, Analgesia

\section{Introduction}

Thyroidectomy is a widely applied surgical procedure for management of thyroid diseases. Many patients may complain of moderate to severe postoperative pain following thyroid surgery particularly during the first postoperative day due to various causes including skin incision, extensive tissue dissection, pharyngolaryngeal discomfort after intubation, neck hyperextension, surgical manipulation and inflammation [1] [2].

Surgical manipulations and inadequate pain control can also induce perioperative complex stress response with neurohumoral, metabolic and immunological changes that may be manifested as an increase in heart rate and blood pressure, hyperglycemia and release of different cytokines [3].

Different techniques or medications including local anesthetics infiltration, non-steroidal anti-inflammatory drugs (NSAID) or opioids have been used for postoperative analgesia. Although (NSAID) may be beneficial analgesics, many surgeons do not prefer them in thyroidectomy patients to limit the risk of postoperative bleeding [4] [5]. On the other hand, opioids have been associated with some adverse events as respiratory depression and frequent postoperative nausea and vomiting [6] [7]. So it was necessary to find safe analgesic techniques for these patients by using either different adjuvant therapies or multimodal analgesia by combining different drugs and techniques with different modes of action to improve the quality of postoperative analgesia and to decrease the doses of systemic opioids and their related side effects [8] [9].

Lidocaine is a local anesthetic drug that produces an analgesic and antihyperalgesic effects by modifying the response of neurons in the dorsal horn to noxious stimuli, and it has an anti-inflammatory effect by inhibiting migration and metabolic activation of leukocytes [10]. Lidocaine can provide these effects through various mechanisms as sodium channel blocking and inhibition of both G protein and NMDA receptors [11] [12]. Many previous studies evaluated the analgesic effect of perioperative IV lidocaine and they concluded that it has postoperative safe analgesic effect when infused at low doses [13] [14] [15]. Other studies suggested that lidocaine can also attenuate surgical stress response through its anti-inflammatory effect [16]. However, the definite mechanism of postoperative analgesic and opioid-sparing effect of intravenous lidocaine is not yet clear, it is considered as more antihyperalgesic than as a direct analgesic [10].

Gabapentin (1-aminomethyl cyclohexane acetic acid) is related to the neurotransmitter gamma-amino butyric acid (GABA), its analgesic effect is mediated 
by binding to the $\alpha_{2} \delta$ subunit of voltage-dependent calcium channels [17]. It was mainly used as an anticonvulsant drug, but it has been detected to be effective in diabetic neuropathy, neuropathic pain, and postherpetic neuralgia [17] [18] [19]. Gabapentin may reduce or prevent acute nociceptive and inflammatory pain especially if given 1 - 2 hours preoperatively. A Previous study had shown synergism between gabapentin and morphine for postoperative analgesia [20]. Some previous meta-analysis reviews stated that gabapentin was an effective adjunct for treatment of the postoperative pain in various procedures and it can be used in multimodal analgesia planes. [21] [22].

The hypothesis of the present study was that the combination of IV lidocaine and oral gabapentin-due to their antihyperalgesic and analgesic effects-would be more effective inreducing postoperative analgesic consumption and providing prolonged postoperative analgesia after thyroid surgery.

The aim of this prospective randomized comparative controlled study was to evaluate and compare the analgesic effects of IV lidocaine infusion or preoperative oral gabapentin and the combination of both drugs in patients undergoing thyroid surgery. The primary outcome was the evaluation of postoperative tramadol consumption and time of the first analgesic request. The secondary outcome was the intraoperative fentanyl consumption, assessment of postoperative pain scores, and evaluation of the effects of these drugs on postoperative nausea and vomiting, sedation and other side effects.

\section{Patients and Methods}

Eighty-eight patients aged 20 - 60 years of American Society of Anesthesiologists classification (ASA) grade I or II scheduled for elective thyroidectomy were enrolled in this study after taking approval from the Ethics Committee of anesthesia department of Kasr El Aini hospital and obtaining a written informed consent from all patients. This study was prospective comparative randomized, double-blind and controlled study, and it was conducted from April 2015 until April 2016 at ENT operating theater of Cairo University hospitals.

Exclusion criteria were: cardiovascular dysfunction, impaired kidney or liver function, uncontrolled diabetes, pregnancy, previous treatment with calciumchannel blockers, anti-arrhythmic drug intake, psychiatric disorders, epilepsy, steroid treatment, or chronic treatment with opioids and sensitivity to the administered drugs. Patients who refused to participate in the study or unable to cooperate were also excluded.

All Patients were randomized into four equal groups according to computer-provided random numbers which were put in opaque sealed envelopes. The four groups were equally distributed ( $\mathrm{n}=22$ per group) as the following:

- Group P (placebo): patients ingested placebo capsules $1 \mathrm{~h}$ before the operation and received IV saline bolus $(10 \mathrm{ml})$ immediately before induction of anesthesia followed by saline infusion which continued intraoperatively until skin closure. 
- Group L (lidocaine): patients ingested placebo capsules $1 \mathrm{~h}$ before surgery, and received IV bolus injection of $1.0 \mathrm{mg} / \mathrm{kg}$ lidocaine (Xylocaine 2\%; AstraZeneca, 600 Capability Green, Luton, LU1 3LU, UK) diluted by normal saline to a $10 \mathrm{ml}$ volume immediately before induction of anesthesia, then a continuous infusion with a syringe pump at a rate of $2 \mathrm{mg} / \mathrm{kg} / \mathrm{h}$ during the operation until skin closure.

- Group G (gabapentin): patients ingested $600 \mathrm{mg}$ gabapentin capsules (Neurontin; Pfizer, Cairo, Egypt) $1 \mathrm{~h}$ before surgery, and received saline bolus (10 $\mathrm{ml}$ ) immediately before induction of anesthesia followed by saline infusion intraoperatively (the same volume as lidocaine infusion in group L) through identical syringe pump until skin closure.

- Group L G (lidocaine + gabapentin): patients ingested $600 \mathrm{mg}$ gabapentin capsules $1 \mathrm{~h}$ before surgery, and received IV bolus of $1.0 \mathrm{mg} / \mathrm{kg}$ lidocaine immediately before the induction of anesthesia followed by intraoperative lidocaine infusion with an identical syringe pump at a rate of $2 \mathrm{mg} / \mathrm{kg} / \mathrm{h}$ intraoperatively until skin closure.

The infusion drugs were prepared by an anesthesiologist who has no further role in the study, the doses of administered IV drugs were calculated according to the patient's body weight and they were supplied as two syringes labeled respectively as: -(Bolus) syringes and (Infusion) syringes.

The surgical team, the patients, the anesthesiologists, and the investigators responsible for collecting intraoperative and postoperative recorded data did not know about the groups' allocation.

Routine preoperative evaluations and assessment of patients were done one day before surgery, also patients were told about using the visual analog score of pain (VAS; $0=$ no pain and $10=$ worst pain imaginable).

\section{Anesthesia Protocol}

On the morning of surgery the patients were shifted to the preparation room and IV cannula was inserted. 1 hour preoperatively patients in groups G and LG received oral gabapentin capsules $600 \mathrm{mg}$, while patients in groups $\mathrm{P}$ and $\mathrm{L}$ received oral placebo capsules. In the operating room routine monitoring (electrocardiogram, pulse oximetry, and noninvasive blood pressure) were applied with recording of baseline $\mathrm{HR},(\mathrm{MAP})$ and arterial oxygen saturation (SpO2). Immediately before induction of anesthesia the patients in $(P)$ and $(G)$ groups received $10 \mathrm{ml}$ of normal saline followed by IV saline infusion until skin closure according to the study design, while patients in group (L) and (LG) received bolus dose of IV lidocaine (of $1.0 \mathrm{mg} / \mathrm{kg}$ ) followed by IV lidocaine infusion (2 $\mathrm{mg} / \mathrm{kg} / \mathrm{h}$ ) intraoperatively until closure of the skin.

Induction of anesthesia started with of intravenous fentanyl $1.5 \mu \mathrm{g} / \mathrm{kg}$, propofol $2 \mathrm{mg} / \mathrm{k}$, then atracurium $0.5 \mathrm{mg} / \mathrm{kg}$ was used to facilitate intubation with the appropriate size cuffed endotracheal tube (ETT), anesthesia was maintained with Sevoflurane $1.5 \%-2 \%$ in $50 \%$ oxygen and air mixture, and top-up doses of 
atracurium $0.15 \mathrm{mg} / \mathrm{kg}$ to maintain muscle relaxation, with adjustment of mechanical ventilation trying to keep end-tidal carbon dioxide (EtCO2) at 30 to 35 $\mathrm{mmHg}$. Lactated ringer solution was infused at $6-8 \mathrm{ml} / \mathrm{kg} / \mathrm{h}$ throughout surgery.

MAP, HR, SpO2 and EtCO2 values were monitored continuously with recording both MAP and HR before induction of anesthesia, after intubation then every 15 min until the end of surgery. Both of MAP and HR were maintained within $\pm 20 \%$ of measured baseline values. Adjusting Sevoflurane concentration and boluses of IV fentanyl 25 - 50 ug were used to manage hypertension (MAP > $20 \%$ of baseline values) or tachycardia (HR $>20 \%$ of baseline values). On the other hand hypotension (MAP $<20 \%$ of measured baseline value) was managed by giving IV bolus of Ringer's solution $(200 \mathrm{ml})$ but if no improvement IV ephedrine boluses (3 - $9 \mathrm{mg}$ ) was used. If bradycardia occurred ( $\mathrm{HR}<50$ beat per minute) IV atropine $0.4 \mathrm{mg}$ boluses were given.

After skin closure, sevoflurane was discontinued and all infusions were terminated, then reversal of muscle relaxation was achieved by IV neostigmine $(0.05 \mathrm{mg} / \mathrm{kg})$ with atropine $(0.02 \mathrm{mg} / \mathrm{kg})$. All Patients were extubated after pharyngeal suctioning and recovery of adequate spontaneous ventilation.

Intraoperative data as hemodynamic parameters, total fentanyl consumption, duration of surgery and extubation time were recorded.

After recovery, all patients were transmitted to the post anesthesia care unit (PACU) and they were observed and monitored for (blood pressure, HR, respiration, and oxygen saturation).

An independent observer assessed postoperative pain by using the visual analog scale (VAS; 0 "no pain" and 10 "worst pain imaginable") at different assessment times (on arriving the PACU which was recorded as the ( 0 hours) then at $2,6,12,18$, and 24 hours after surgery). Postoperative analgesia was provided by tramadol $1 \mathrm{mg} / \mathrm{kg}$ which was given over 2 - 5 minutes intravenously when the VAS score exceeded or equal 4 (VAS $\geq 4$ ), with the recording of the total amount of IV tramadol given in the postoperative 24 hours and recording the time to the first postoperative analgesic request.

Sedation level was assessed and scored at the same times of assessment of VAS of pain. Scoring was as follows: 1 = awake and alert; 2 = awake but drowsy, responding to verbal stimulus; 3 = drowsy but arousable, responding to physical stimulus, and $4=$ unarousable, do not respod to physical stimulus.

Postoperatively, patients were also observed to detect the incidence of side effects, such as nausea, vomiting (two or more episodes of vomiting were treated with intravenous ondansetron $4 \mathrm{mg}$ ), respiratory depression, dizziness, dry mouth restlessness and signs of systemic toxicity of lidocaine such as perioral numbness, drowsiness, lightheadedness and metallic taste were also checked.

Outcomes and assessment:

- The primary outcome measure was total postoperative analgesic (tramadol) consumption and time of the first request for postoperative analgesic. 
Secondary outcome measures were;

- Intraoperative hemodynamic changes (MAP and HR)and intraoperative fentanyl consumption

- Postoperative pain assessment by VAS during 24 hours.

- Postoperative sedation level.

- Side effects; nausea and vomiting, dizziness, headache and respiratory depression.

\section{Sample Size}

According to previous studies [23] [24], it was found that the minimum optimum sample size should be (19) patients in each group to detect a significant difference of more than $20 \%$ in postoperative opioid consumption with using a power of $80 \%$ and a significance level of 5\%. Considering anticipated dropouts, the sample size was increased to 22 patients per group. Sample size calculation was made by using $G$ * Power software version 3.1.2 for MS Windows, Franz Faul, Kiel University, Germany.

\section{The Statistical Analysis}

The computer program SPSS (Statistical Package for the Social Science; SPSS Inc, Chicago, IL, USA) version 22 was used for statistical analysis Data were statistically described in terms of mean \pm standard deviation $( \pm S D)$, or frequencies (number of cases) and percentages when appropriate. one-way analysis of variance (ANOVA) test was used for comparison between the four study groups, and Mann Whitney $U$ test for independent samples for comparing not-normal data. Bonferroni correction for multiple comparisons was applied in all comparisons. Categorical data were compared by using Chi-square $\left(\chi^{2}\right)$ test, while Exact test was used instead if the expected frequency is less than 5. $p$ values less than 0.05 was considered statistically significant.

\section{Results}

Eighty-eight patients undergoing thyroid surgery under general anesthesia completed this study, patients were divided into four equal groups (22 patients in each group). Details of allocation, randomization, follow up and the final number of patients analyzed in the study are represented in Figure 1.

No statistically significant difference was detected between all groups regarding the age, gender, ASA status, the weight, duration of surgery and extubation time (Table 1).

There was a significant decrease in intraoperative fentanyl requirement in the combination group (LG) if compared to the placebo (P) group, lidocaine (L) group and $(\mathrm{G})$ group $(\mathrm{p}<0.001)$. Also, the intraoperative fentanyl consumption was significantly lower in both lidocaine group (L) and gabapentin (G) group when compared to placebo group $(P)(p<0.001)$. No significant difference between $(\mathrm{L})$ and $(\mathrm{G})$ groups when compared to each other (Table 1). 


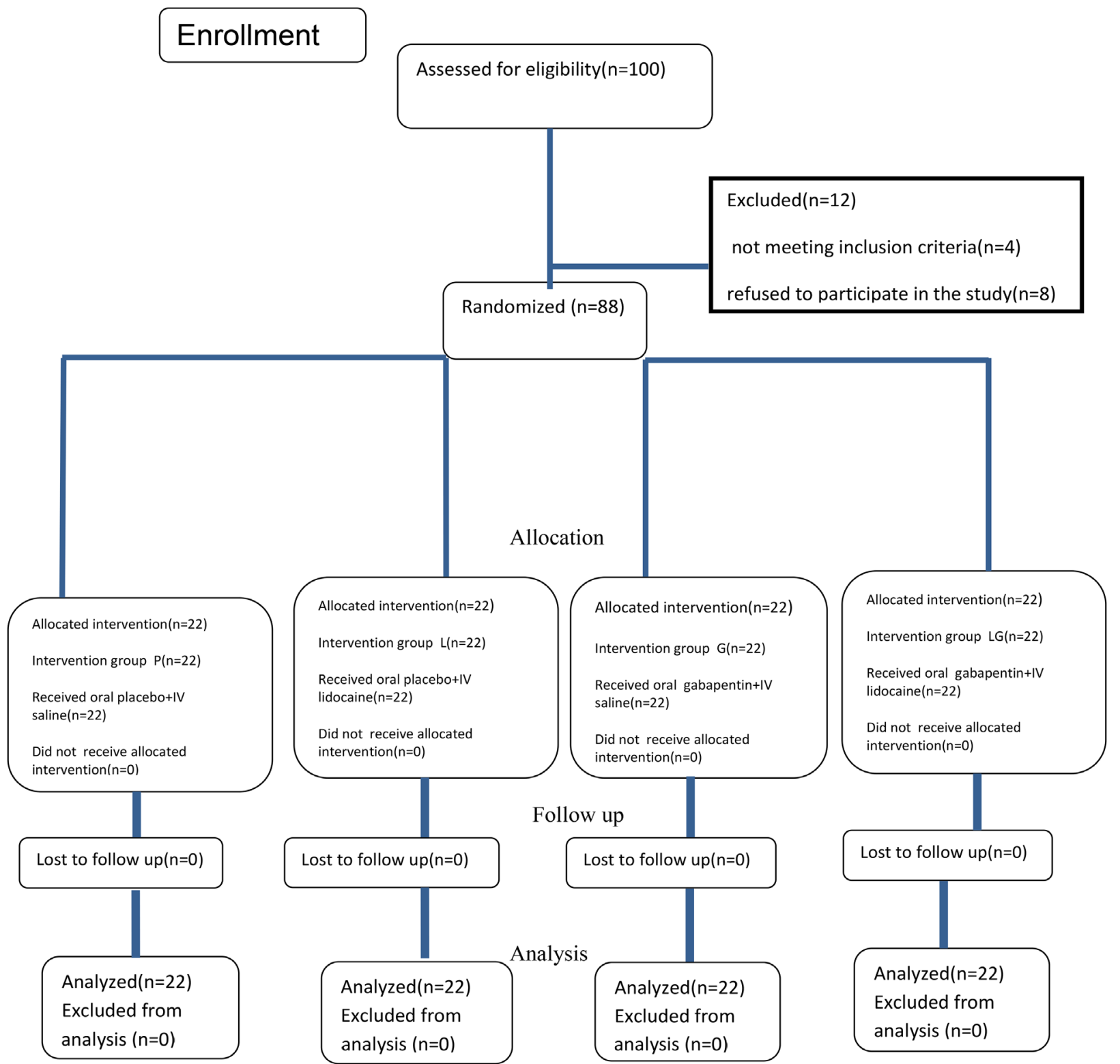

Figure 1. CONSORT Flow diagram of the studied patients enrolled in the study.

Table 1. Patients demographic data and intraoperative characteristics.

\begin{tabular}{cccccc}
\hline Variables & (p) group $(\mathrm{n}=22)$ & $(\mathrm{L})$ group $(\mathrm{n}=22)$ & (G) group $(\mathrm{n}=22)$ & (LG) group $(\mathrm{n}=22)$ & P value \\
\hline Age (years) & $45.6 \pm 7.5$ & $46.9 \pm 7.7$ & $45.4 \pm 6.7$ & $47.58 \pm 8.2$ & 0.755 \\
Male/Female (n) & $6 / 16$ & $6 / 16$ & $5 / 17$ & $7 / 15$ & 0.876 \\
ASA class I/II (n) & $7 / 15$ & $8 / 14$ & $6 / 16$ & $8 / 14$ & 0.904 \\
Weight (kg) & $87.5 \pm 9.5$ & $89 \pm 8.7$ & $90.2 \pm 8.2$ & $88.7 \pm 8.6$ & 0.787 \\
Duration of surgery (min) & $127 \pm 27$ & $130 \pm 28$ & $134 \pm 29$ & $132 \pm 28$ & 0.861 \\
Intraoperative fentanyl consumption (ug) & $283 \pm 38.7^{\mathrm{a}, \mathrm{b}, \mathrm{c}}$ & $227 \pm 39.8^{\mathrm{c}}$ & $220 \pm 34.2^{\mathrm{c}}$ & $180 \pm 30.4$ & $<0.001$ \\
extubation time (min) & $10.1 . \pm 1.8$ & $10.4 \pm 1.4$ & $9.8 \pm 1.7$ & $10.6 \pm 1.2$ & 0.341 \\
\hline
\end{tabular}

Data are represented as mean \pm SD or numbers. ASA = American Society of Anesthesiologists; $(\mathrm{P})$ group = Placebo group, $(\mathrm{L})$ group $=$ Lidocaine group, $(\mathrm{G})$ group $=$ Gabapentin group, $(\mathrm{LG})$ group $=$ Lidocaine-Gabapentin group; a: significant difference compared to group L $(p<0.001)$; b: significant difference compared to group $\mathrm{G}(p<0.001)$; c: significant difference compared to group LG $(p<0.001)$. 
Intraoperative $\mathrm{HR}$ and MAP of the placebo $(\mathrm{P})$ group were significantly higher than the other 3 groups after intubation and after 15 min with $p$ value $(0.001$ and $\mathrm{p}<0.001)$ respectively for HR, and $\mathrm{p}<0.001$ after intubation and after 15 min for MAP, but no statistically significant difference was found among the groups at other times (Table 2, Table 3). There was no serious bradycardia or hypotension in the four groups.

Table 2. Intraoperative heart rate (HR).

\begin{tabular}{cccccc}
\hline Time & $\begin{array}{c}\text { (p) group } \\
(\mathrm{n}=22)\end{array}$ & $\begin{array}{c}(\mathrm{L}) \text { group } \\
(\mathrm{n}=22)\end{array}$ & $\begin{array}{c}(\mathrm{G}) \text { group } \\
(\mathrm{n}=22)\end{array}$ & $\begin{array}{c}(\mathrm{LG}) \text { group }) \\
(\mathrm{n}=22)\end{array}$ & P value \\
\hline Before induction & $84.5 \pm 17.6$ & $86.4 \pm 16.5$ & $85.8 \pm 16.7$ & $82.2 \pm 15.6$ & 0.834 \\
After intubation & $101.4 \pm 12.5^{\mathrm{a}, \mathrm{b}, \mathrm{c}}$ & $90.2 \pm 7.8$ & $90.6 \pm 6.7$ & $89.4 \pm 9.5$ & $<0.001$ \\
After 15 min & $98.4 \pm 10.9^{\mathrm{a}, \mathrm{b}, \mathrm{c}}$ & $87.6 \pm 7.8$ & $86.7 \pm 6.9$ & $86.5 \pm 7.1$ & $<0.001$ \\
After 30 min & $90.6 \pm 8.7$ & $87.7 \pm 7.9$ & $88.4 \pm 8.2$ & $87.9 \pm 8.4$ & 0.638 \\
After 45 min & $89.4 \pm 8.7$ & $86.5 \pm 8.2$ & $87.7 \pm 8.4$ & $85.8 \pm 8.8$ & 0.525 \\
After 60 min & $88.8 \pm 7.6$ & $86.7 \pm 7.4$ & $89.6 \pm 8.2$ & $85.9 \pm 7.9$ & 0.355 \\
Aftern 75 min & $92.3 \pm 8.8$ & $91.4 . \pm 7.8$ & $90.1 \pm 7.9$ & $90.2 \pm 7.8$ & 0.775 \\
After 90 min & $90.7 \pm 9.9$ & $88.6 \pm 8.2$ & $87.3 \pm 8.4$ & $89.4 \pm 8.6$ & 0.631 \\
At end of surgery & $93.6 \pm 7.7$ & $90,7 \pm 8.9$ & $91.4 \pm 8.4$ & $89.4 \pm 8.2$ & 0.404 \\
\hline
\end{tabular}

Data are represented as mean $\pm \mathrm{SD}$, $(\mathrm{P})$ group = Placebo group, $(\mathrm{L})$ group = Lidocaine group, $(\mathrm{G})$ group = Gabapentin group, (LG) group = Lidocaine-Gabapentin group; a: significant difference compared to group $\mathrm{L}(\mathrm{p}=0.001)$ after intubation and $(\mathrm{p}<0.001)$ after $15 \mathrm{~min}$; b: significant difference compared to group $\mathrm{G}$ ( $\mathrm{p}$ $=0.001)$ after intubation and $(\mathrm{p}<0.001)$ after $15 \mathrm{~min}$; : significant difference compared to group LG ( $\mathrm{p}=$ $0.001)$ after intubation and $(\mathrm{p}<0.001)$ after $15 \mathrm{~min}$.

Table 3. Changes in mean arterial pressure (MAP).

\begin{tabular}{cccccc}
\hline Time & $\begin{array}{c}\text { (p) group } \\
(\mathrm{n}=22)\end{array}$ & $\begin{array}{c}\text { (L) group } \\
(\mathrm{n}=22)\end{array}$ & $\begin{array}{c}(\mathrm{G}) \text { group } \\
(\mathrm{n}=22)\end{array}$ & $\begin{array}{c}\text { (LG) group } \\
(\mathrm{n}=22)\end{array}$ & P value \\
\hline Before induction & $94.5 \pm 11.6$ & $95.4 \pm 12.2$ & $94.8 \pm 12.4$ & $92.5 \pm 11.9$ & 0.868 \\
& $114.6 \pm 12.7^{\mathrm{a}, \mathrm{b}, \mathrm{c}}$ & $99.2 \pm 10.8$ & $98.6 \pm 11.6$ & $96.9 \pm 12.6$ & $<0.001$ \\
After intubation & & & & & \\
After 15 min & $110.6 \pm 10.4^{\mathrm{a}, \mathrm{b}, \mathrm{c}}$ & $94.6 \pm 9.8$ & $93.7 \pm 10.2$ & $92.4 \pm 10.3$ & $<0.001$ \\
After 30 min & $96.3 \pm 10.4$ & $95.4 \pm 10.9$ & $94.8 \pm 10.7$ & $93.8 \pm 11.7$ & 0.894 \\
After 45 min & $95.8 \pm 9.6$ & $93.7 \pm 10.2$ & $94.7 \pm 10.6$ & $92.4 \pm 10.2$ & 0.720 \\
After 60 min & $94.8 \pm 12.2$ & $92.6 \pm 11.8$ & $93.9 \pm 11.7$ & $92.6 \pm 12.1$ & 0.911 \\
After 75 min & $94.5 \pm 10.8$ & $93.8 \pm 10.5$ & $93.5 \pm 11.4$ & $91.5 \pm 11.6$ & 0.828 \\
After 90 min & $95.6 \pm 9.8$ & $92.5 \pm 10.1$ & $93.4 \pm 9.6$ & $92.4 \pm 9.2$ & 0.671 \\
At end of surgery & $95.7 \pm 11.4$ & $93.2 \pm 10.8$ & $94.6 \pm 12.2$ & $93.8 \pm 12.8$ & 0.907 \\
\hline
\end{tabular}

Data are represented as mean $\pm \mathrm{SD}$; $(\mathrm{P})$ group $=$ Placebo group, $(\mathrm{L})$ group = Lidocaine group, $(\mathrm{G})$ group $=$ Gabapentin group, $(\mathrm{LG})$ group = Lidocaine-Gabapentin group; a: significant difference compared to group $\mathrm{L}(\mathrm{p}<0.001)$; b: significant difference compared to group $\mathrm{G}(\mathrm{p}<0.001)$; c: significant difference compared to group LG $(\mathrm{p}<0.001)$. 
The average total postoperative tramadol consumption for group (P), (L), (G) and (LG) was ( $256 \pm 44$ vs $155 \pm 38$ vs $148 \pm 31$ vs $120 \pm 15 \mathrm{mg}$ ) respectively (p < 0.001 ) with the lowest value in the combination group (LG) which was statistically lower when compared to $(\mathrm{P}),(\mathrm{L})$ and $(\mathrm{G})$ groups $(\mathrm{p}<0.001)$, Also, both (L) and $(\mathrm{G})$ groups had statistically lower values when compared to $(\mathrm{P})$ group $(\mathrm{p}<$ 0.001) (Table 4).

Regarding the average time of the first postoperative analgesic requirement for group (P), (L), (G) and (LG) it was $(47.5 \pm 30.7$ vs $117.5 \pm 27.6$ vs $189.5 \pm$ 33.8 vs $208.6 \pm 39.7 \mathrm{~min}$ ) respectively $(\mathrm{p}<0.001)$. The time of the first request of analgesic was significantly prolonged in the combination group (LG) compared to $(\mathrm{P})$ and $(\mathrm{L})$ groups $(\mathrm{p}<0.001)$. Also, there was significantly longer time of the first request of analgesics in both $(\mathrm{L})$ and $(\mathrm{G})$ groups than placebo $(\mathrm{P})$ group $(\mathrm{p}<$ 0.001 ). and prolonged time in $(G)$ group compared to $(L)$ group ( $p<0.001$ ) (Table 4).

Regarding the VAS; the combination group had the lowest VAS compared to other groups. When compared to placebo the combination group had significantly lower VAS during the first 12 hours $(\mathrm{p}<0.001)$.

The combination group (LG) was also superior to lidocaine (L) group with significant lower VAS at ( 0 and 6 hours) ( $p<0.001$, while $\mathrm{p}<0.05$ at 2 hours). Similarly, a significant difference was seen between (LG) group and (G) group (p $<0.01$ at 0 hour) and $\mathrm{p}<0.001$ at 6 hours) Figure 2).

On comparing group $(\mathrm{G})$ with the placebo group $(\mathrm{P})$, postoperative VAS had significantly lower values in group $(G)(p<0.01$ at 0 hour and $p<0.001$ at 2,6 hours and $\mathrm{p}<0.05$ at 12 hours). There was significantly lower VAS in group G when compared to L group only at 6 hours $(\mathrm{p}<0.05)$.

On comparing group (L) with placebo group $(\mathrm{P})$ visual analogue scale was significantly lower in group $(\mathrm{L})$ at 0 and 2 hours $(\mathrm{P}<0.01$ and $\mathrm{P}<0.001$ respectively).

Table 4. Total tramadol consumption and time for the first analgesic request.

\begin{tabular}{|c|c|c|c|c|c|c|}
\hline & $(\mathrm{p})$ group $(\mathrm{n}=22)$ & (L) group $(\mathrm{n}=22)$ & $(\mathrm{G})$ group $(\mathrm{n}=22)$ & $(\mathrm{LG})$ group) $(\mathrm{n}=22)$ & & P Value \\
\hline $\begin{array}{l}\text { Postoperative } \\
\text { tramadol } \\
\text { consumption } \\
(\mathrm{mg})\end{array}$ & $256 \pm 44^{\mathrm{a}, \mathrm{b}, \mathrm{c}}$ & $155 \pm 38^{c}$ & $148 \pm 31^{c}$ & $120 \pm 15$ & $<0.001$ & $\begin{array}{l}(P) \text { vs }(\mathrm{L})<0.001 \\
(\mathrm{P}) \text { vs }(\mathrm{G})<0.001 \\
(\mathrm{P}) \text { vs }(\mathrm{LG})<0.001 \\
(\mathrm{~L}) \text { vs }(\mathrm{G}) 0.507 \\
(\mathrm{~L}) \text { vs }(\mathrm{LG})<0.001 \\
\text { (G) vs }(\mathrm{LG})<0.001\end{array}$ \\
\hline $\begin{array}{l}\text { Time to first } \\
\text { analgesic } \\
\text { request (min) }\end{array}$ & $47.5 \pm 30.7^{\mathrm{a}, \mathrm{b}, \mathrm{c}}$ & $117.5 \pm 27.6^{b, c}$ & $189.5 \pm 33.8$ & $208.6 \pm 39.7$ & $<0.001$ & $\begin{array}{l}(P) \text { vs }(L)<0.001 \\
(P) \text { vs }(G)<0.001 \\
(P) \text { vs }(L G)<0.001 \\
(L) \text { vs }(G)<0.001 \\
(L) \text { vs }(L G)<0.001 \\
\text { (G) vs }(L G) 0.093\end{array}$ \\
\hline
\end{tabular}

Data are mean $\pm \mathrm{SD}(\mathrm{P})$ group = Placebo group, $(\mathrm{L})$ group = Lidocaine group,$(\mathrm{G})$ group = Gabapentin group, $(\mathrm{LG})$ group = Lidocaine-Gabapentin group; : significant difference compared to group L $(\mathrm{p}<0.001)$; b: significant difference compared to group $\mathrm{G}(\mathrm{p}<0.001)$; c: significant difference compared to group LG $(\mathrm{p}<0.001)$. 


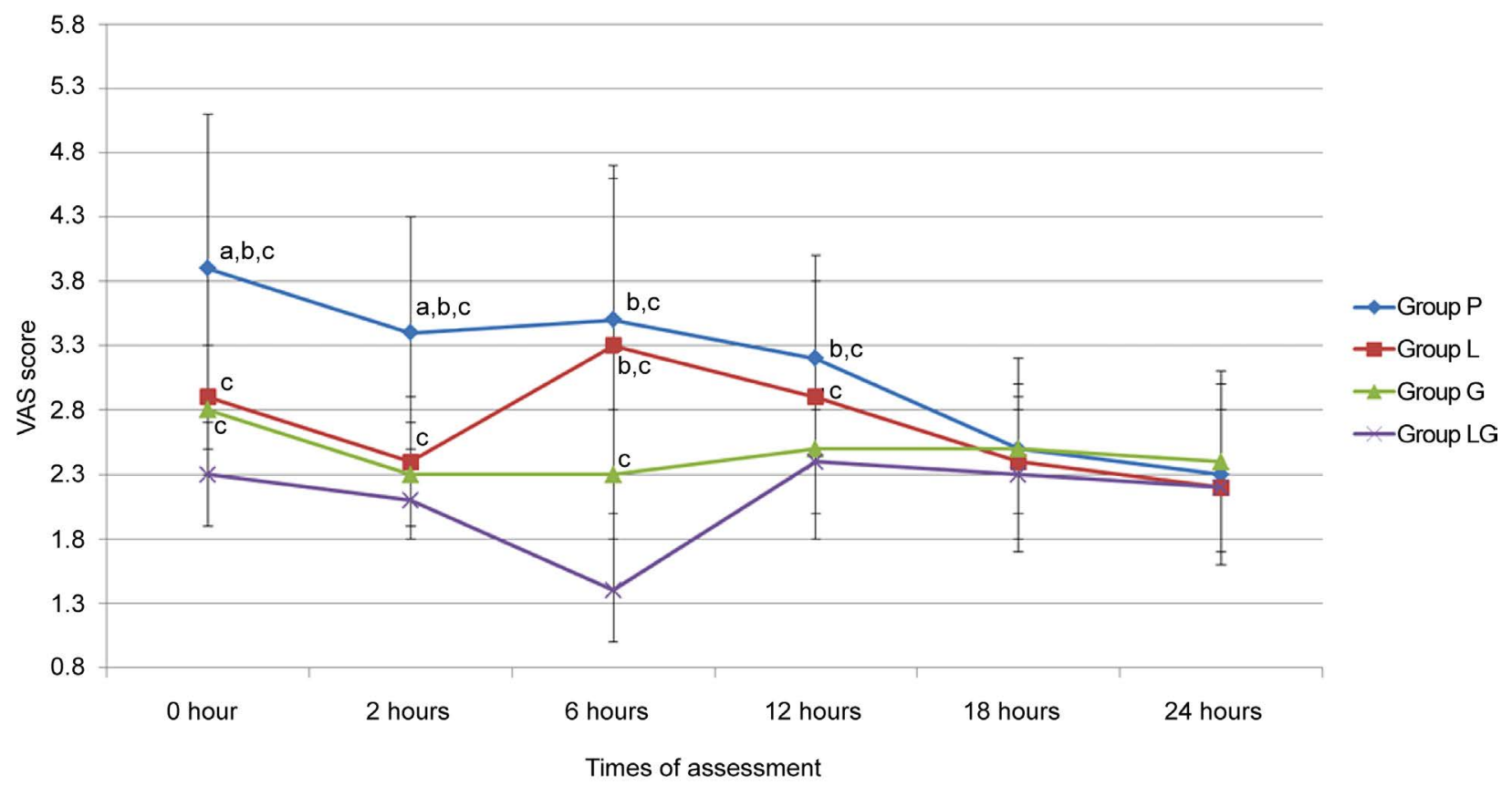

Figure 2. Comparison of postoperative visual analog scale (VAS) between all groups; (P) group = Placebo group, $(\mathrm{L})$ group = Lidocaine group, $(\mathrm{G})$ group = Gabapentin group, (LG) group = Lidocaine-Gabapentin group; a: significant difference compared to group L ( $\mathrm{p}<0.01$ at 0 hour and $\mathrm{p}<0.001$ at 2 hour in group $\mathrm{P}$ compared to group L); b: significant difference compared to group G: (in group P compared to group Gp $<0.01$ at 0 hour and $p<0.001$ at 2, 6 hours and $p<0.05$ at 12 hours); (in group L compared to group G p < 0.05 at 6 hour); c: significant difference compared to group LG: (in group P compared to group LG p $<0.001$ at 0,2 6,12 hours); (in group L compared to group LG $p<0.001$ at 0,6 hours and $p<0.05$ at 2 hours); (in group G compared to group LG $\mathrm{p}<0.01$ at 0 hour, and $\mathrm{p}<0.001$ at 6 hours).

Regarding the sedation score, there were no statistically significant differences between all groups (Figure 3).

There was a higher incidence of postoperative nausea and vomiting in group (P) with statistically significant difference between $P$ group and $G$ and LG groups $(\mathrm{p}<0.01)$ (Table 5).

Other complication did not show significant difference between all groups ( $\mathrm{P}>0.05$ for all) as shown in Table 5 . No patient had any respiratory complication during the postoperative period.

There were no complaints related to lidocaine toxicity in L and LG groups.

\section{Discussion}

The results of this study detected that the group received a combination of preoperative oral gabapentin and intraoperative IV lidocaine infusion had the lowest postoperative tramadol consumption and the longest time period before the first request for postoperative analgesia. It also showed lower VAS pain scores, lower intraoperative fentanyl consumption and lower incidence of postoperative nausea and vomiting. Both IV lidocaine infusion group and oral gabapentin group had a superior analgesic effect compared to the placebo group. There was a significant reduction of postoperative nausea and vomiting in the gabapentin and the combination groups than the placebo group. 


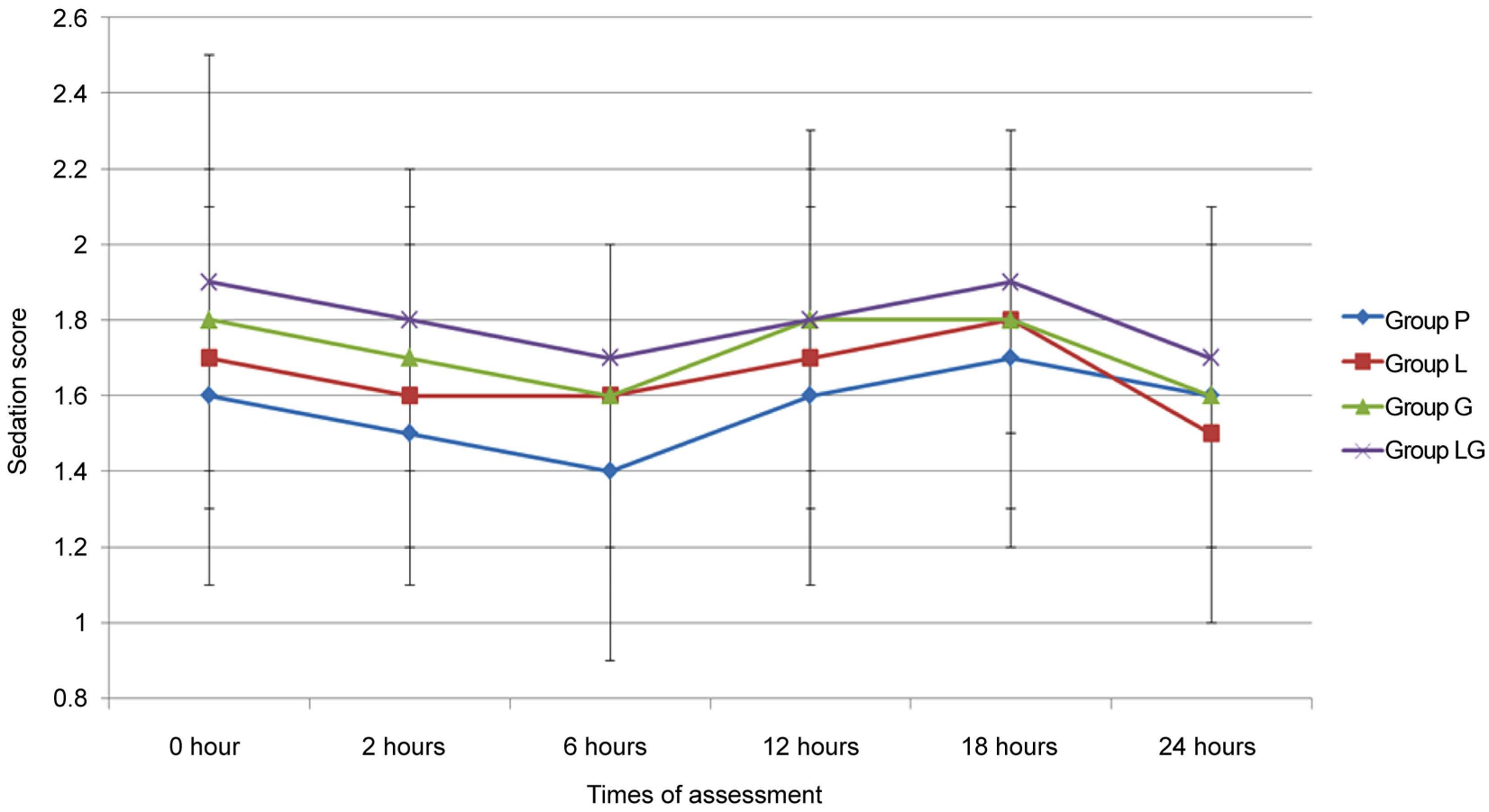

Figure 3. Comparison of Postoperative Sedation Score between all groups; (P) group = Placebo group, (L) group = Lidocaine group, $(\mathrm{G})$ group = Gabapentin group, $(\mathrm{LG})$ group = Lidocaine-Gabapentin group; $\mathrm{P}>0.05$ for all groups.

Table 5. Postoperative side effects.

\begin{tabular}{|c|c|c|c|c|c|}
\hline Postoperative side effects & $(\mathrm{P})$ group $(\mathrm{n}=22)$ & $(\mathrm{L})$ group $(\mathrm{n}=22)$ & $(\mathrm{G})$ group $(\mathrm{n}=22)$ & $(\mathrm{LG})$ group $(\mathrm{n}=22)$ & $\mathrm{P}$ value \\
\hline Nausea & $10(45.5 \%)^{\mathrm{b}, \mathrm{c}}$ & $5(22.7 \%)$ & $2(9 \%)$ & $2(9 \%)$ & $<0.01$ \\
\hline Vomiting & $10(45.5 \%)^{\mathrm{b}, \mathrm{c}}$ & $4(18.1 \%)$ & $2(9 \%)$ & $1(4.5 \%)$ & $<0.01$ \\
\hline dizziness & $3(13 \%)$ & $4(18 \%)$ & $6(27 \%)$ & $7(31 \%)$ & 0.459 \\
\hline headache & $3(13.6 \%)$ & $4(18.1 \%)$ & $3(13.6 \%)$ & $4(18.1 \%)$ & 0.952 \\
\hline Dry mouth & $5(22.7 \%)$ & $4(18.1 \%)$ & $6(27.2 \%)$ & $6(27.2 \%)$ & 0.876 \\
\hline
\end{tabular}

Data are numbers or \%; $(\mathrm{P})$ group = Placebo group, $(\mathrm{L})$ group = Lidocaine group, $(\mathrm{G})$ group = Gabapentin group, $(\mathrm{LG})$ group = Lidocaine-Gabapentin group; b: significant difference compared to group $\mathrm{G}(\mathrm{p}<0.01)$; c: significant difference compared to group $\mathrm{LG}(\mathrm{p}<0.01)$.

Although both IV lidocaine infusion [13] [14] [15] [16] and oral preoperative gabapentin [20] [21] [22] proved to be effective in the management of acute postoperative pain following many surgical procedures with reported significant lower VAS values and reduced postoperative analgesic consumption, but some studies and meta-analyses showed contrasting results regarding the analgesic effect of lidocaine [25] and gabapentin due to differences in used doses and used regimens or time of application [21]-[27] with the need of more researches to specify the actual value of both drugs for providing sufficient analgesia in various surgical procedures.

In the current study lidocaine was found to improve post-operative analgesia only in the early postoperative period and decreased postoperative tramadol 
consumption compared to placebo group. These results were in line with the previous study of Lauwick et al. [14] where IV lidocaine (1.5 mg/kg) was administered, followed by continuous lidocaine infusion $(2 \mathrm{mg} / \mathrm{kg} / \mathrm{h})$ throughout surgery in patients undergoing laparoscopic cholecystectomy, the lidocaine group had lower postoperative fentanyl consumption compared to the control group $(\mathrm{P}=0.018)$, with reduction of the amount of desflurane required $(\mathrm{P}=$ 0.012). The analgesic effect of IV lidocaine was also proved by the study of Koppert et al. [26] where a group of 20 patients undergoing major abdominal surgery received lidocaine bolus dose $(1.5 \mathrm{mg} / \mathrm{kg})$ in $10 \mathrm{~min}$, then intraoperative IV infusion of lidocaine $(1.5 \mathrm{mg} / \mathrm{kg} / \mathrm{h}$ )and another group (20 patients) received saline placebo. Lidocaine group reported less pain during movement and less postoperative morphine requirement $(\mathrm{P}<0.05)$. Also, Wu CT et al. detected a significant higher analgesic effect of IV lidocaine compared to control group in patients undergoing laparoscopic cholecystectomy with significant lower VAS and total meperidine consumption [28].

The study of Kaba et al. [29] detected improved postoperative analgesia by IV lidocaine infusion in patients undergoing laparoscopic colectomy where a bolus injection of intravenous lidocaine $(1.5 \mathrm{mg} / \mathrm{kg})$ was given to a group of patients at induction of anesthesia, followed by intraoperative lidocaine continuous infusion $(2 \mathrm{mg} \cdot \mathrm{kg} / \mathrm{h})$ then $1.33 \mathrm{mg} \cdot \mathrm{kg} \cdot \mathrm{h}$ postoperatively for $24 \mathrm{~h}$, while an equal volume of saline infusion was given to the control group, Lidocaine significantly reduced postoperative pain and opioid consumption $(\mathrm{P}=0.005)$. Similarly, another study [23] comparing intraoperative IV lidocaine infusion to IV magnesium infusion and placebo infusion, it reported that both lidocaine and magnesium infusion reduced pain scores $(\mathrm{p}<0.05)$, and reduced intraoperative fentanyl requirements and postoperative morphine consumption $(\mathrm{p}<0.001)$ when compared to the placebo group, these results support the results of the current study.

The results of the current study correlate with those of the previous study done by Farag et al. [30] where patients received IV lidocaine infusion (2 $\mathrm{mg} \cdot \mathrm{kg} \cdot \mathrm{h}$ ) or IV placebo infusion during complex spine surgery, with continuation of infusion in the post anesthesia care unit, the lidocaine group had significantly lower pain scores $(\mathrm{P}<0.001)$, also, lidocaine infusion decreased postoperative opioid consumption by approximately $25 \%$.

On the contrary to the current study, lidocaine has not proven as an effective analgesic in previous studies showing no reduction in pain scores or opioid consumption in various surgical procedures as found in the study of Martin et al. [31] on patients undergoing total hip arthroplasty where the patients of lidocaine group received lidocaine bolus $1.5 \mathrm{mg} / \mathrm{kg}$ followed by $1.5 \mathrm{mg} \cdot \mathrm{kg} \cdot \mathrm{h}$ IV infusion while the control group received normal saline, they found no analgesic benefit or opioid sparing effect of IV lidocaine. Also, De Oliveira and co-authors [32] detected no significant difference in pain severity and no difference in postoperative supplemental morphine consumption in two groups of patients 
undergoing abdominal hysterectomy, where the lidocaine group received lidocaine $(2 \mathrm{mg} / \mathrm{kg} / \mathrm{h})$ and the control group received $0.9 \%$ saline.

The lack of analgesic effect of IV lidocaine infusion was also detected in other studies [33] [34] [35], the discrepancy between these results and the current study may be due to the differences in the infused doses of lidocaine or different timing of administration and different types and regions of surgery which may affect the patterns of peripheral and central sensitization. Another explanation of these contrasting results may be related to the individual variation in pain thresholds and the response of different groups of patients to different analgesic drugs.

In the current study, gabapentin was found to improve post-operative analgesia with significantly lower pain scores, lower intraoperative and postoperative analgesic consumption, with prolonged time of first analgesic request (if compared to placebo group). These findings were consistent with the previous studies on adult patients undergoing tonsillectomy, where patients who received gabapentin (1200 mg or $600 \mathrm{mg}$ ) showed reduction of the amount of analgesics used in the first $24 \mathrm{~h}$ after surgery [36] [37].

The analgesic effect of gabapentin was detected in the study of Sen et al. [38] in patients undergoing abdominal hysterectomy, which compared the effect of gabapentin $1200 \mathrm{mg}$ to ketamine group which ingested oral placebo capsules, then IV bolus of ketamine $0.3 \mathrm{mg} / \mathrm{kg}$ before incision then $0.05 \mathrm{mg} / \mathrm{kg} / \mathrm{hour}$ IV infusion of ketamine until the end of operation; they detected that group received gabapentin had significantly lower pain scores compared to ketamine and control groups with significant decreased opioid requirement in gabapentin and ketamine groups compared to control group $(\mathrm{P}<0.001)$.

The results of the current study are in concordance with the results of the study conducted by Al-Mujadi et al. [24] which compared gabapentin $1200 \mathrm{mg}$ to oral placebo in patients undergoing thyroidectomy and they detected significantly lower pain scores at rest and during swallowing with significantly lower postoperative morphine consumption $(\mathrm{P}<0.001)$ in the gabapentin group.

The results of the current study were also in agreement with many previous studies carried out to evaluate the effect of preoperative gabapentin in many surgical procedures including hysterectomy [39]. cholecystectomy [40], caesarean delivery [41] and orthopedic procedures [42] [43] they all proved that gabapentin significantly decreased the acute postoperative pain scores and opioid requirements.

On the other hand, the results of the present study were in contrast to Bartholdy et al. study [44] which revealed that oral gabapentin $1200 \mathrm{mg}$ given preoperatively in laparoscopic sterilization had no significant reduction in pain score as compared to placebo. It may be explained by the short preoperative time of giving oral gabapentin ( $30 \mathrm{~min}$ before surgery) while it reaches peak plasma concentration within $2-3 \mathrm{~h}$.

Also, on the contrary to the current study, Short et al. [45] did not find any 
improvement in post cesarean section VAS scores with using either 300 or 600 $\mathrm{mg}$ gabapentin as a single preoperative dose. This contradictory results may be attributed to the different type of surgery and anesthesia (spinal anesthesia).

Thyroid surgery commonly had a high incidence of postoperative nausea and vomiting (PONV). The exact mechanisms of PONV after thyroidectomy are not yet clear, but it may be related to stimulation of vagal afferents and increased surgical inflammatory responses caused by surgical injury of the neck structures [46]. In the current study, the incidence of nausea and vomiting were significantly lower in both gabapentin group and combination groups compared to placebo group, but no significant difference was found in lidocaine group if compared to placebo. These results were in accordance with previous studies using perioperative IV lidocaine during surgery with no effect on PONV [14] [30], while in other studies lidocaine could reduce nausea and vomiting, this may be mediated by a reduction in ileus as most of these studies were conducted in abdominal surgery [25].

Previous studies detected a lower incidence of PONV with preoperative gabapentin [47] [48] and this was in accordance with the current study. The definite mechanism to reduce nausea and vomiting with gabapentin is not yet known, but it may be related to the anxiolytic effect of gabapentin together with lower postoperative opioid consumption.

On the contrary, no significant difference in the incidence of PONV was noticed in Turan study evaluating the analgesic effects of gabapentin $1200 \mathrm{mg}$ given 1 hour before total abdominal hysterectomy [39].

The current study showed comparable postoperative sedation level between all groups, which was in accordance with many previous studies [39] [41] [45].

In contrast to our study, the previous study of Ghai et al. [49] comparing between three groups of patients undergoing abdominal hysterectomy where the Patients received either $300 \mathrm{mg}$ pregabalin, or gabapentin capsules $900 \mathrm{mg}$ or placebo capsules given at $1-2$ hours before surgery, patients of gabapentin and pregabalin groups had significantly higher sedation scores compared to placebo group $(\mathrm{P}<0.001)$.

This contradictory in results of postoperative sedation may be related to different doses of gabapentin used in different procedures as using higher or repeated doses commonly increase postoperative sedation as reported in previous meta-analysis studies, also the use of different scores for assessment of sedation may cause these contradictory in results [21] [22].

The other adverse effect related to gabapentin (dizziness and headache) were comparable to other groups in the current study, which correlates with the results of previous meta-analysis studies concluded that gabapentin considered to have an optimum postoperative analgesic effect with the lowest incidence of adverse effects when used in the dose of $600-800 \mathrm{mg}$ [21] [22].

The current study had some limitations, one of them is lack of measuring the plasma lidocaine level. but the administered dose of lidocaine was smaller with 
shorter duration of IV infusion than that used in previous studies in which the lidocaine did not reach a toxic levels and in which there were no side effects reported [29] [33].

Both intravenous lidocaine and oral gabapentin may be considered as safe, inexpensive non-opioid analgesics helping to improve the quality of postoperative analgesia. More studies are needed to confirm these results in various types of surgery. Moreover, the effective safe dose of each drug, the onset time and duration of analgesia need more clinical studies to be conducted with larger sample size.

\section{Conclusion}

Administration of intravenous lidocaine infusion or oral gabapentin had a significant postoperative analgesic effect in patients undergoing thyroid surgery. The combination of preoperative gabapentin and intraoperative IV lidocaine infusion was more effective than either drug alone with lower postoperative analgesic requirements, more prolonged time of first postoperative analgesic request and lower VAS. There was significantly lower incidence of PONV in the groups received gabapentin.

\section{References}

[1] Kalmovich, L.M., Cote, V., Sands, N., Black, M., Payne, R. and Hier, M. (2010) Thyroidectomy Exactly How Painful Is It? Journal of Otolaryngology - Head \& Neck Surgery, 39, 277-283.

[2] Rutledge, J., Siegel, E, Belcher, R., Bodenner, D. and Stack, B.C. (2014) Barriers to Same-Day Discharge of Patients Undergoing Total and Completion Thyroidectomy. Otolaryngology-Head and Neck Surgery, 150, 770-774. https://doi.org/10.1177/0194599814521568

[3] Singh, M. (2003) Stress Response and Anesthesia Altering the Peri and PostOperative Management. Indian Journal of Anaesthesia, 47, 427-434.

[4] Fourcade, O., Sanchez, P., Kern, D., Mazoit, J.X., Minville, V. and Samii, K. (2005) Propacetamol and Ketoprofen after Thyroidectomy. European Journal of Anaesthesiology, 22, 373-377. https://doi.org/10.1017/S0265021505000645

[5] Mathiesen, O., Wetterslev, J., Kontinen, V.K., Pommergaard, H.C., Nikolajsen, L., Rosenberg, J., et al. (2014) Adverse Perioperative Paracetamol, NSAIDs, Glucocorticoids, Gabapentinoids and Their Combinations: A Topical Review. Acta Anaesthesiologica Scandinavica, 58, 1182-1198. https://doi.org/10.1111/aas.12380

[6] Motamed, C., Merle, J.C., Yakhou, L., Combes, X., Vodinh, J., Kouyoumoudjian, C., et al. (2006) Postoperative Pain Scores and Analgesic Requirements after Thyroid Surgery: Comparison of Three Intraoperative Opioid Regimens. International Journal of Medical Sciences, 3, 11-13. https://doi.org/10.7150/ijms.3.11

[7] Porreca, F. and Ossipov, M.H. (2009) Nausea and Vomiting Side Effects with Opioid Analgesics during Treatment of Chronic Pain: Mechanisms, Implications, and Management Options. Pain Medicine, 10, 654-662. https://doi.org/10.1111/j.1526-4637.2009.00583.x

[8] White, P.F. (2005) The Changing Role of Non Opioid-Analgesic Techniques in the Management of Postoperative Pain. Anesthesia \& Analgesia, 101, S5-S22. 
https://doi.org/10.1213/01.ANE.0000177099.28914.A7

[9] Ziemann-Gimmel, P., Hensel, P., Koppman, J. and Robert, M. (2013) Multimodal Analgesia Reduces Narcotic Requirements and Antiemetic Rescue Medication in Laparoscopic Roux-en-Y Gastric Bypass Surgery. Surgery for Obesity and Related Diseases, 9, 975-980. https://doi.org/10.1016/j.soard.2013.02.003

[10] Hollman, M. and Durieux, M.E. (2000) Local Anesthetics and the Inflammatory Response: A New Therapeutic Indication? Anesthesiology, 93, 858-875. https://doi.org/10.1097/00000542-200009000-00038

[11] Hollmann, M.W., Strumper, D., Herroeder, S. and Durieux, M. (2005) Receptors, G Proteins, and Their Interactions. Anesthesiology, 103, 1066-1078. https://doi.org/10.1097/00000542-200511000-00022

[12] Sugimoto, M., Uchida, I. and Mashimo, T. (2003) Local Anaesthetics Have Different Mechanisms and Sites of Action at the Recombinant N-Methyl-D-Aspartate (NMDA) Receptors. British Journal of Pharmacology, 138, 876-882. https://doi.org/10.1038/sj.bjp.0705107

[13] Yardeni, I.Z., Beilin, B., Mayburd, E., Levinson, Y. and Bessler, H. (2009) The Effect of Perioperative Intravenous Lidocaine on Postoperative Pain and Immune Function. Anesthesia \& Analgesia, 109, 1464-1469. https://doi.org/10.1213/ANE.0b013e3181bablbd

[14] Lauwick, S., Kim do, J., Michelagnoli, G., Mistralett, G., Feldman, L., Fried, G., et al. (2008) Intraoperative Infusion of Lidocaine Reduces Postoperative Fentanyl Requirements in Patients Undergoing Laparoscopic Cholecystectomy. Canadian Journal of Anesthesia, 55, 754-760. https://doi.org/10.1007/BF03016348

[15] McKay, A., Gottschalk, A., Ploppa, A., Durieux, M. and Groves, D. (2009) Systemic Lidocaine Decreased the Perioperative Opioid Analgesic Requirements But Failed to Reduce Discharge Time after Ambulatory Surgery. Anesthesia \& Analgesia, 109, 1805-1808. https://doi.org/10.1213/ANE.0b013e3181be371b

[16] Kuo, C.P., Jao, S.W., Chen, K.M., Wong, C.S., Yeh, C.C., Sheen, M.J., et al. (2006) Comparison of the Effects of Thoracic Epidural Analgesia and i.v. Infusion with Lidocaine on Cytokine Response, Postoperative Pain and Bowel Function in Patients Undergoing Colonic Surgery. British Journal of Anaesthesia, 97, 640-646. https://doi.org/10.1093/bja/ael217

[17] Maneuf, Y.P., Gonzalez, M.I., Sutton, K.S., Chung, F.Z., Pinnock, R.D. and Lee, K. (2003) Cellular and Molecular Action of the Putative GABA-Mimetic, Gabapentin. Cellular and Molecular Life Sciences, 60, 742-750. https://doi.org/10.1007/s00018-003-2108-x

[18] Backonja, M., Beydoun, A., Edwards, K.R., Schwartz, S.L., Fonseca, V., Hes, M., et al. (1998) Gabapentin for the Symptomatic Treatment of Painful Neuropathy in Patients with Diabetes Mellitus: A Randomized Controlled Trial. JAMA, 280, 1831-1836. https://doi.org/10.1001/jama.280.21.1831

[19] Rowbotham, M., Harden, N., Stacey, B., Bernstein, P. and Magnus-Miller, L. (1998) Gabapentin for the Treatment of Postherpetic Neuralgia: A Randomized Controlled Trial. JAMA, 280, 1837-1842. https://doi.org/10.1001/jama.280.21.1837

[20] Eckhardt, K., Ammon, S., Hofmann, U., Riebe, A., Gugeler, N. and Mikus, G. (2000) Gabapentin Enhances the Analgesic Effect of Morphine in Healthy Volunteers. Anesthesia \& Analgesia, 91, 185-191.

[21] Hurley, R.W., Cohen, S.P., Williams, K.A., Rowlingson, A.J., Wu, C.L. (2006) The Analgesic Effects of Perioperative Gabapentin on Postoperative Pain: A Meta-Analysis. Regional Anesthesia and Pain Medicine, 31, 237-247. 
https://doi.org/10.1097/00115550-200605000-00011

[22] Mathiesen, O., Moiniche, S. and Dahl, J.B. (2007) Gabapentin and Postoperative Pain: A Qualitative and Quantitative Systematic Review with Focus on Procedure. BMC Anesthesiology, 7, 7-16. https://doi.org/10.1186/1471-2253-7-6

[23] Saadawy, I.M., Kaki, A.M., Abd El Latif, A.A., Abd-Elmaksoud, A.M. and Tolba, O.M. (2010) Lidocaine vs. Magnesium: Effect on Analgesia after a Laparoscopic Cholecystectomy. Acta Anaesthesiologica Scandinavica, 54, 549-556. https://doi.org/10.1111/j.1399-6576.2009.02165.x

[24] Al-Mujadi, H., A-Refai, A.R., Katzarov, M.G., Dehrab, N.A., Batra, Y.K. and Al-Qattan, A.R. (2006) Preemptive Gabapentin Reduces Postoperative Pain and Opioid Demand Following Thyroid Surgery. Canadian Journal of Anesthesia, 53, 268-273. https://doi.org/10.1007/BF03022214

[25] Ventham, N.T., Kennedy, E.D., Brady, R.R., Paterson, H.M., Speake, D., Foo, I., et al. (2015) Efficacy of Intravenous Lidocaine for Postoperative Analgesia Following Laparoscopic Surgery: A Meta-Analysis. World Journal of Surgery, 39, 2220-2234. https://doi.org/10.1007/s00268-015-3105-6

[26] Koppert, W., Weigand, M., Neumann, F., Sittl, R., Schuettler, J., Schmelz, M., et al. (2004) Perioperative intravenous Lidocaine Has Preventive Effects on Postoperative Pain and Morphine Consumption after Major Abdominal Surgery. Anesthesia \& Analgesia, 98, 1050-1055. https://doi.org/10.1213/01.ANE.0000104582.71710.EE

[27] Dahl, J.B., Mathiesen, O. and Moiniche, S. (2004) 'Protective Premedication': An Option with Gabapentin and Related Drugs? A Review of Gabapentin and Pregabalin in the Treatment of Post-Operative Pain. Acta Anaesthesiologica Scandinavica, 48, 1130-1136. https://doi.org/10.1111/j.1399-6576.2004.00484.x

[28] Wu, C.T., Borel, C.O., Lee, M.S., Yu, J.C., Liou, H.S., Yi, H.D., et al. (2005) The Interaction Effect of Perioperative Co-Treatment with Dextromethorphan and Intravenous Lidocaine on Pain Relief and Recovery of Bowel Function after Laparoscopic Cholecystectomy. Anesthesia \& Analgesia, 100, 448-453. https://doi.org/10.1213/01.ANE.0000142551.92340.CC

[29] Kaba, A., Laurent, S.R., Detroz, B.J., Sessler, D.I., Durieux, M.E., Lamy, M.L., et al. (2007) Intravenous Lidocaine Infusion Facilitates Rehabilitation after Laparoscopic Colectomy. Anesthesiology, 106, 11-18. https://doi.org/10.1097/00000542-200701000-00007

[30] Farag, E., Ghobrial, M., Sessler, D.I., Dalton, J.E., Liu, J., Lee, J.H., et al. (2013) Effect of Perioperative Intravenous Lidocaine Administration on Pain, Opioid Consumption, and Quality of Life after Complex Spine Surgery. Anesthesiology, 119, 932-940. https://doi.org/10.1097/ALN.0b013e318297d4a5

[31] Martin, F., Cherif, K., Gentili, M.E., Enel, D., Abe, E., Alvarez, J.C., et al. (2008) Lack of Impact of Intravenous Lidocaine on Analgesia, Functional Recovery, and Nociceptive Pain Threshold after Total Hip Arthroplasty. Anesthesiology, 109, 118-123. https://doi.org/10.1097/ALN.0b013e31817b5a9b

[32] De Oliveira, C.M.B., Sakata, R.K., Slullitel, A., Salomão, R., Lanchote, V.L. and Issy, AM. (2015) Effect of Intraoperative Intravenous Lidocaine on Pain and Plasma Interleukin-6 in Patients Undergoing Hysterectomy. Brazilian Journal of Anesthesiology, 65, 92-98. https://doi.org/10.1016/j.bjan.2013.07.017

[33] Bryson, G.L., Charapov, I., Krolczyk, G., Taljaard, M. and Reid, D. (2010) Intravenous Lidocaine Does Not Reduce Length of Hospital Stay Following Abdominal Hysterectomy. Canadian Journal of Anesthesia, 57, 759-766.

https://doi.org/10.1007/s12630-010-9332-2 
[34] Menezes, C., Luciana, C.L., Lee, M.C. and Marcelo, M.V. (2015) Intravenous Lidocaine for Postmastectomy Pain Treatment; Randomized Blind Placebo Controlled Clinical Trial. Brazilian Journal of Anesthesiology, 65, 207-212. https://doi.org/10.1016/j.bjane.2014.05.017

[35] Grigoras, A., Lee, P., Sattar, F. and Shorten, G. (2012) Perioperative Intravenous Lidocaine Decreases the Incidence of Persistent Pain after Breast Surgery. The Clinical Journal of Pain, 28, 567-572. https://doi.org/10.1097/AJP.0b013e31823b9cc8

[36] Mikkelsen, S., Hilsted, K.L., Andersen, P.J., Hjortso, N.C., Enggaard, T.P., Jorgensen, D.G., et al. (2006) The Effect of Gabapentin on Post-Operative Pain Following Tonsillectomy in Adults. Acta Anaesthesiologica Scandinavica, 50, 809-815. https://doi.org/10.1111/j.1399-6576.2006.01057.x

[37] Jeon, E.J., Park, Y.S., Park, S.S., Lee, S.K. and Kim, D.H. (2009) The Effectiveness of Gabapentin on Post-Tonsillectomy Pain Control. European Archives of Oto-Rhino-Laryngology, 266, 1605-1609. https://doi.org/10.1007/s00405-008-0897-0

[38] Sen, H., Sizlan, A., Yanarates, O., Emirkadi, H., Ozkan, S., Dagli, G. and Turan, A. (2009) A Comparison of Gabapentin and Ketamine in Acute and Chronic Pain after Hysterectomy. Anesthesia \& Analgesia, 109, 1645-1650.

https://doi.org/10.1213/ANE.0b013e3181b65ea0

[39] Turan, A., Karamanlioglu, B., Memis, D., Usar, P., Pamukçu, Z. and Türe, M. (2004) The Analgesic Effects of Gabapentin after Total Abdominal Hysterectomy. Anesthesia \& Analgesia, 98, 1370-1373. https://doi.org/10.1213/01.ANE.0000108964.70485.B2

[40] Pandey, C.K., Priye, S., Singh, S., Singh, U., Singh, R.B. and Singh, P.K (2004) Preemptive Use of Gabapentin Significantly Decreases Postoperative Pain and Rescue Analgesic Requirements in Laparoscopic Cholecystectomy. Canadian Journal of Anesthesia, 51, 358-363. https://doi.org/10.1007/BF03018240

[41] Moore, A., Costello, J., Wieczorek, P., Shah, V., Taddio, A. and Carvalho, J.C. (2011) Gabapentin Improves Postcesarean Delivery Pain Management: A Randomized, Placebo-Controlled Trial. Anesthesia \& Analgesia, 112, 167-173. https://doi.org/10.1213/ANE.0b013e3181fdf5ee

[42] Menigaux, C., Adam, F., Guignard, B., Sessler, D.I. and Chauvin, M. (2005) Preoperative Gabapentin Decreases Anxiety and Improves Early Functional Recovery from Knee Surgery. Anesthesia \& Analgesia, 100, 1394-1399.

https://doi.org/10.1213/01.ANE.0000152010.74739.B8

[43] Pandey, C.K., Sahay, S., Gupta, D., Ambesh, S.P., Singh, R.B., Raza Raza, M., et al. (2004) Preemptive Gabapentin Decreases Postoperative Pain after Lumbar Discoidectomy. Canadian Journal of Anesthesia, 51, 986-989. https://doi.org/10.1007/BF03018484

[44] Bartholdy, J., Hilsted, K.L., Hjortsoe, N.C., Engbaek, J. and Dahi, J. (2006) Effect of Gabapentin on Morphine Demand and Pain after Laparoscopic Sterilization Using Filshie Clips. A Double Blind Randomized Clinical Trial. BMC Anesthesiology, 6, 12. https://doi.org/10.1186/1471-2253-6-12

[45] Short, J., Downey, K., Bernstein, P., Shah, V. and Carvalho, J. (2012) A Single Preoperative Dose of Gabapentin Does Not Improve Postcesarean Delivery Pain Management: A Randomized, Double-Blind, Placebo-Controlled Dose-Finding Trial. Anesthesia \& Analgesia, 115, 1336-1342. https://doi.org/10.1213/ANE.0b013e31826ac3b9

[46] Gauger, P.G., Shanks, A., Morris, M., Greenfield, M.L., Burney, R.E. and O’Reilly, 
M. (2008) Propofol Decreases Early Postoperative Nausea and Vomiting in Patients Undergoing Thyroid and Parathyroid Operations. World Journal of Surgery, 32, 1525-1534. https://doi.org/10.1007/s00268-008-9472-5

[47] Pandey, C., Priye, S., Ambesh, S., Singh, S., Singh, U. and Singh, P. (2006) Prophylactic Gabapentin for Prevention of Postoperative Nausea and Vomiting in Patients Undergoing Laparoscopic Cholecystectomy: A Randomized, Double-Blind, Placebo-Controlled Study. Journal of Postgraduate Medicine, 52, 97-100.

[48] Achuthan, S., Singh, I., Varthya, S.B., Srinivasan, A., Chakrabarti, A. and Hota, D. (2015) Gabapentin Prophylaxis for Postoperative Nausea and Vomiting in Abdominal Surgeries: A Quantitative Analysis of Evidence from Randomized Controlled Clinical Trials. British Journal of Anaesthesia, 114, 588-597. https://doi.org/10.1093/bja/aeu449

[49] Ghai, A., Gupta, M., Hooda, M., Singla, D. and Wadhera, R. (2011) A Randomized Controlled Trial to Compare Pregabalin with Gabapentin for Postoperative Pain in Abdominal Hysterectomy. Saudi Journal of Anaesthesia, 5, 252-257.

https://doi.org/10.4103/1658-354X.84097

\section{Submit or recommend next manuscript to SCIRP and we will provide best} service for you:

Accepting pre-submission inquiries through Email, Facebook, LinkedIn, Twitter, etc. A wide selection of journals (inclusive of 9 subjects, more than 200 journals)

Providing 24-hour high-quality service

User-friendly online submission system

Fair and swift peer-review system

Efficient typesetting and proofreading procedure

Display of the result of downloads and visits, as well as the number of cited articles

Maximum dissemination of your research work

Submit your manuscript at: http://papersubmission.scirp.org/

Or contact ojanes@scirp.org 